\title{
Fenthion Compound Degradation in the Pesticide Bayleton 500 ec in Sonolysis, Ozonolysis and Sonozolysis with Addition of $\mathrm{TiO}_{2}$-anatase
}

\author{
Sofiyanita, Zona Octaria \\ Chemical Education of the State Islamic University Sultan Syarif Kasim Riau \\ * E-mail: sofiyanita10@gmail.com
}

\begin{abstract}
Fenthion an active compound contained in EC 500 lebaycid pesticides that are toxic. To reduce the level of toxicity will be degradation in sonolysis, ozonolysis and sonozolysis with the addition of TiO2-anatase. Degradation results in sonolysis, ozonolysis and sonozolysis measured by UV-Vis spectrophotometer at wavelength of 400-600 nm. From the research that has been made degradation result fenthion $6 \mathrm{mg} / \mathrm{L}$ in sonolysis without addition of catalyst of $37.5 \%$ and with the addition of $\mathrm{TiO} 2$-anatase catalyst obtained for $65.12 \%$ of degradation for 60 minutes. In ozonolysis at the same time obtained percent degradation of $39.77 \%$ without the addition of catalyst and $81 \%$ with the addition of TiO2-anatase catalyst. Percent degradation fenthion compound without the addition of TiO2-anatase catalyst after a 60-minute sonozolysis obtained at $91.7 \%$.
\end{abstract}

Keywords: Fenthion, Sonolysis, Ozonolysis, Sonozolysis, TiO2-anatase catalyst

\section{Introduction}

The rapid development in the field of science along with the progress of development in the field of industry and technology has spurred humans to be able to meet the needs of life in order to achieve a safety, guarantee and high quality of life. However, various problems arise, one of which is the widespread use of pesticides that can cause negative impacts both directly and indirectly on human health and the environment.

Pesticides are chemical substances used to kill or control various pests. The word pesticide comes from the word "pest", which means pest and "cide" which means killer. So simply pesticides are defined as pest killers. The understanding of pests for farmers is very broad, namely mites, disturbing plants, plant diseases caused by fungi (bacteria), bacteria and viruses, then nematodes (worms that damage the roots), snails, rats, birds and other animals that are considered detrimental [1]. Pesticides can be classified as pollutants or pollutants [2].

Fenthion is an organophosphate compound that is used to eradicate insects in garlic, peanut, cocoa, soybean, quinine, pepper and tobacco plants .Fenthion with the molecular formula $\mathrm{C}_{10} \mathrm{H}_{15} \mathrm{O}_{3} \mathrm{PS}_{2}$ is the active ingredient of lebaycid insecticides. The name IUPAC from Fenthion is O-Dimethyl O- [3-methyl-4- (methylthio) phenyl] phosphorothioate or O, O-Dimethyl O-4methylthio-m-tolyl phosphorothioate. This compound is a colorless liquid, almost odorless and soluble in glyceride, methanol, ethanol, ether, acetone, and most organic solvents. 


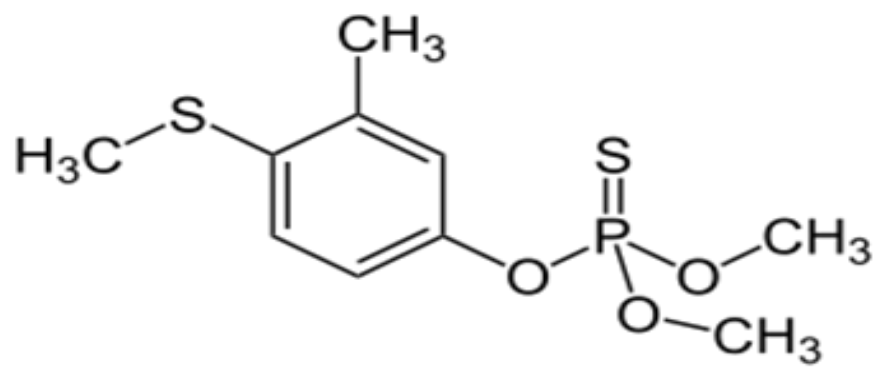

Figure 1. Chemical Structure of Fenthion

Several methods of treatment of conventional waste have been carried out, including sedimentation and absorption by activated carbon. However, conventional waste treatment is less effective, Karen cannot remodel the structure of organic compounds, but only move them from one place to another. Therefore, it is necessary to look for other alternative methods that are more effective to decompose the waste, namely the sonolysis method, ozonolysis and sonozolysis.

Ozonolysis is a method of degradation of organic compounds using ozone $\left(\mathrm{O}_{3}\right)$, where there is a breakdown between $\mathrm{C}=\mathrm{C}$ to produce a $\mathrm{C}=\mathrm{O}$ double bond [3]. The results of this degradation depend on the type of double bond oxidized and the treatment conditions. In the water phase, ozone can be broken down by hydroxide ions, $\mathrm{OH}-$, or conjugate bases of $\mathrm{H}_{2} \mathrm{O}_{2}\left(\mathrm{HO}_{2}-\right)$ into $\mathrm{HO}_{2}$ and $\mathrm{OH}$ radicals which can help the degradation of organic compounds in pesticides [4]. Sonolysis is one method used to degrade organic compounds in aqueous media using vibration (ultrasonic waves). To speed up the reaction, catalysts are usually used in the sonolysis process [5].

Sonolysis is one method of degradation of organic compounds in water media using ultrasonic vibrations that operate at frequencies of $20-500 \mathrm{kHz}$, which in the process will produce hydroxyl radicals and cavitation effects that can break water into $\mathrm{OH}$ radicals. These hydroxyl radicals will degrade fenthion into simpler compounds.

The use of $\mathrm{TiO} 2$ as a catalyst in the degradation process has been developed. Previous results showed that Rhodamine B was degraded $90 \%$ using TiO2-anatase catalyst in sonolysis for 6 hours, and $68.48 \%$ with the addition of $\mathrm{TiO} 2$-rutile [6]. The use of $\mathrm{TiO} 2$-anatase catalyst has also been carried out on the degradation of 2,4 (dichlorophenoxy) acetic acid, which resulted in a percentage of degradation of $95.42 \%$ after irradiation for 90 minutes with stirring [7]. Paraquat was degraded $50.39 \%$ after diozonolysis for 60 minutes [8] and alizarin was degraded by $100 \%$ after irradiation for 30 minutes [9]. and Dikofol compound degraded by $86.13 \%$ after irradiated for 180 minutes with the addition of $\mathrm{TiO} 2$-anatase [10]. Besides that, degradation of dyestuffs and pesticides by sonolysis and photolysis with the addition of $\mathrm{TiO} 2$-anatase catalysts has been done before. Dyestuffs that have been degraded such as Naphtol Blue Black, Sudan I, and Methanil yellow [1113]. whereas pesticides that have been degraded such as Triadimefon compounds in Bayleton 200 EC pesticides and carbaryl in Sevin $85 \mathrm{~S}$ pesticides [14-15].

High Performance Liquid Chromatography (HPLC) is used for qualitative and quantitative analysis. Pesticide analysis using HPLC has previously been carried out such as the determination of multi-drug pesticides in wine [16]. Confidor 200 SL pesticide analysis using HPLC was also carried out by Nurhamidah [17] in which the mobile phase ratio of acetonitrile was obtained: water is 60: 40 , with a flow rate of $0.74 \mathrm{ml} /$ minute and a retention time of 3 minutes.

71 IEKSAKTA: Berkala IImiah Bidang MIPA (Science Periods EKSAKTA of MIPA) 
Based on the description above, research will be conducted to degrade fenthion compounds by sonolysis, ozonolysis and sonozolysis without and with the addition of $\mathrm{TiO}_{2}$-anatase to find out how many fenthion can be degraded with the three methods and compare which methods are more effective to degrade fenthion compounds. so that this research can be used as a reference to degrade pesticide compounds in the environment.

\section{Experimental Section}

\subsection{Tools and Materials}

The tool used in this study is a UV / VIS Spectrophotometer (UV-1700 pharmaspec UV-Vis Spectrophotometer, Shimadzu) to measure absorban compound fenthion. Ultrasonic VC-1 with a frequency of $45 \mathrm{kHz} 60$ watts of power (As One Comp, Japan), is used to degrade fenthion compounds. Ozone reactor (Bio-ozone space age sterilizer, Natural Health Science Sdn. Bhd, Malaysia), which is used as an ozone-producing reactor. Membrane filter (advantac brand membrane filter, polymer: mixed cellulose ester $(0.45 \mu \mathrm{m}, 25 \mathrm{~mm})$, which is used to filter anatase $\mathrm{TiO} 2$ from solution, thermometer is used to regulate temperature, and glass equipment used to make reagents.

The material used in this study is the fenthion compound solution in pesticides Lebaycid 500 EC (Bayer), $\mathrm{TiO}_{2}$ - anatase (Ishihara Sangyo, Ltd, Japan), and distilled water as solvent

\subsection{Methods used}

\subsubsection{Making Fenthion Solution $500 \mathrm{mg} / \mathrm{L}$}

To make a Fenthion solution of $500 \mathrm{mg} / \mathrm{L}$, dissolve $100 \mu \mathrm{L}$ of lebaycid $500 \mathrm{EC}$, then put it in a $100 \mathrm{~mL}$ volumetric flask. The solution is diluted using distilled water.

\subsubsection{Spectrum Fenthion Measurement}

A solution of $500 \mathrm{mg} / \mathrm{L}$ Fenthion was diluted to 2, 4, 6, 8 and $10 \mathrm{mg} / \mathrm{L}$, with respect to the five variations of the solution concentration, each of the absorption spectrum was measured by UV spectrophotometer. Then absorbance data is taken at wavelengths that provide maximum absorption.

\subsubsection{Fenthion Degradation in Sonolysis Without and with Addition of TiO2-anatase}

A total of $20 \mathrm{~mL}$ of fenthion solution was inserted $6 \mathrm{mg} / \mathrm{L}$ into 4 bottles of sonolysis, then degradation was carried out with a time variation of 20,40,60,80 (minutes). Then the absorbance of each solution was determined which was disolized by UV spectrophotometer. Next, the percentage of degradation is calculated. For degradation by adding the same treatment catalyst as above then adding $10 \mathrm{mg}$ of $\mathrm{TiO} 2$-anatase.

\subsubsection{Degradation of Fenthion Ozonolysis Without and with Addition of TiO2-anatase} A total of $20 \mathrm{~mL}$ of $6 \mathrm{mg} / \mathrm{L}$ Fenthion solution were inserted into Erlenmeyer. Then degradation is carried out by flowing ozone into the solution at a time variation of 20, 40, 60, 80 (minutes). Then the absorbance of each solution has been determined which has been ozololized by UV spectrophotometer. By using this absorptive data, the percentage of degradation is calculated. For degradation by adding the same treatment catalyst as above then adding $10 \mathrm{mg}$ of $\mathrm{TiO} 2-$ anatase. 


\subsubsection{Fenthion Degradation with Combined Sonolysis and Ozonolysis (Sonozolysis) with Addition of $\mathrm{TiO}_{2}$-anatase}

A total of $20 \mathrm{~mL}$ of $6 \mathrm{mg} / \mathrm{L}$ solution which has been added with $\mathrm{TiO}_{2}$-anatase as much as $10 \mathrm{mg}$ each into a sonolysis bottle and disposed of in sonolysis equipment. Then degradation is carried out by flowing ozone into the solution while disonolysis at 20, 40, 60, 80 (minutes). Then determine the absorbance of each solution that has been ozololized by UV spectrophotometer. By using the absorbance of this data, the calculation of degradation is done.

To calculate the degradation value, namely:

Degradation percentage $=\underline{\text { initial absorbance } \times 100 \%}$

final absorbance

\section{Results and Discussion}

\subsection{Fenthion Absorption Spectrum Measurement}

Measurement of fenthion absorption spectrum with concentrations of $2,4,6,8 \mathrm{mg} / \mathrm{L}$ using a UV / Vis spectrophotometer at a wavelength of $400-800 \mathrm{~nm}$.

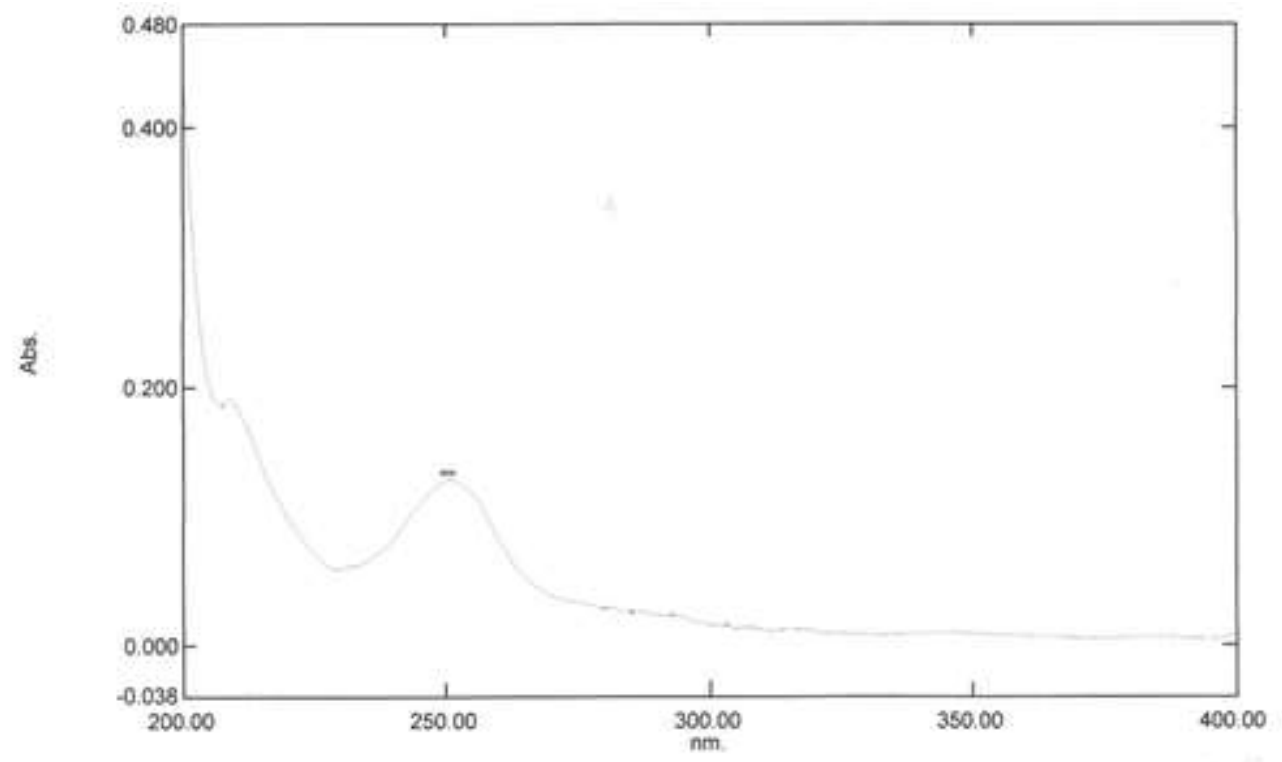

Figure 2. Fenthion Absorption Spectrum

Fenthion absorption spectrum measurement results show a maximum absorption peak of 250.8 nm. From this maximum absorption spectrum, it can be calculated the value of its molten absorptivity using the Lambert-Beer law.[6] Absorbance value data on several variations of concentration and calculation of molar absorption and calibration curve graph can be seen in table 1:

73 IEKSAKTA: Berkala IImiah Bidang MIPA

(Science Periods EKSAKTA of MIPA) 
Table 1. Data on absorptive values:

\begin{tabular}{cc}
\hline Concentrations & Absorbance \\
\hline 2 & 0,088 \\
4 & 0,178 \\
6 & 0,246 \\
8 & 0,330 \\
\hline
\end{tabular}

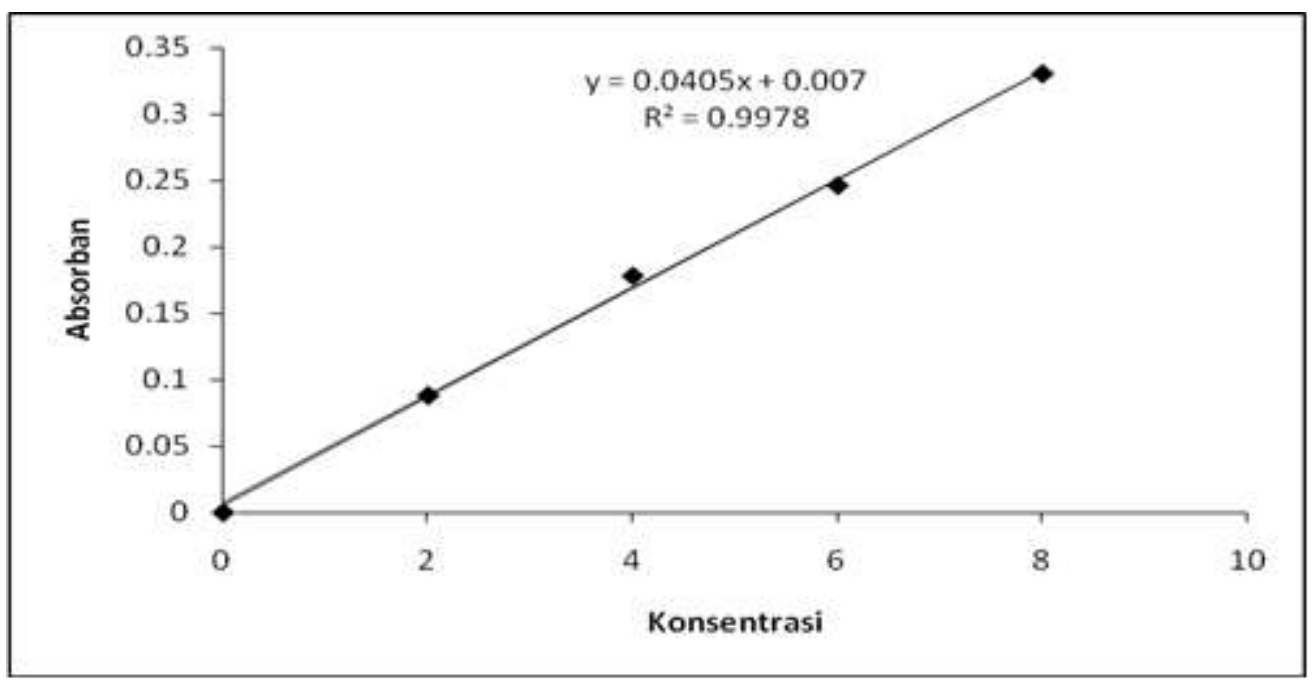

Figure 3. Standard Fenthion Calibration Curve

\subsection{Fenthion degradation sonolysis without and with the addition of $\mathrm{TiO}_{2}$-anatase}

Sonolysis fenthion is $6 \mathrm{mg} / \mathrm{L}$ without and with the addition of TiO2-anatase is carried out for 80 minutes at a time interval of 20 minutes. The results of the degradation can be seen in Figure 2 


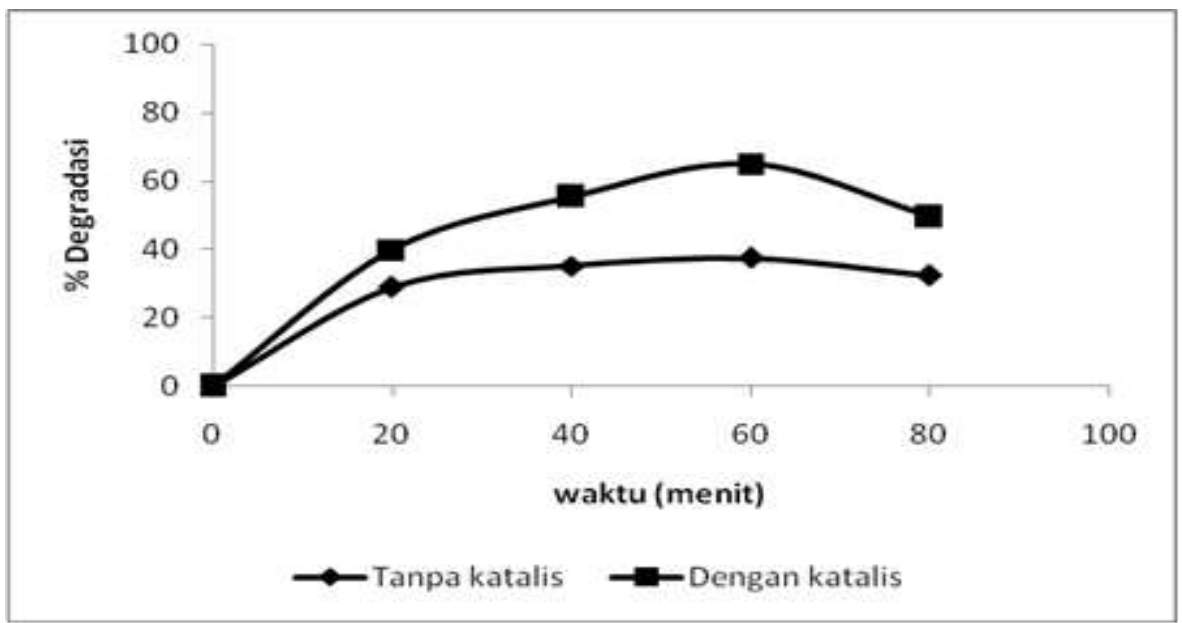

Figure 4. Degradation curve of fenthion sonolysis without and with the addition of $\mathrm{TiO}_{2}$-anatase

In Figure 2 shows that the percentage of degradation continues to increase for 60 minutes with the percentage of degradation as much as $39.77 \%$ without the addition of $\mathrm{TiO}_{2}$-anatase and $81 \%$ with the addition of $\mathrm{TiO}_{2}$-anatase, because the longer the time ozonolysis the more $\mathrm{O}_{3}$ is channeled into the fenthion solution $6 \mathrm{mg} / \mathrm{L}$, the more $\pi$ bonds in the fenthion compound that break up and produce $\mathrm{OH}$ radicals. But at 80 minutes the degradation experienced a degradation of $33.5 \%$. This is due to the long flow of ozone causing the ozone solution to become unstable because ozone will turn into oxygen.

Absorption data and percentage of fenthion degradation were $6 \mathrm{mg} / \mathrm{L}$ for 80 minutes ozonolysis without and with the addition of $\mathrm{TiO}_{2}$-anatase can be seen in table

Tabel 2. Absorban value data and percentage of fenthion degradation by ozonolysis without $\mathrm{TiO}_{2}$ anatase addition

\begin{tabular}{ccc}
\hline Time & A & \% degradation \\
\hline 0 & 0,176 & 0 \\
20 & 0,144 & 18,18 \\
40 & 0,127 & 27,84 \\
60 & 0,106 & 39,77 \\
80 & 0,117 & 33,50 \\
\hline
\end{tabular}

Table 3. Absorban value data and percentage of fenthion degradation by ozonolysis with $\mathrm{TiO}_{2}$ anatase addition

Time A degradation

75 IEKSAKTA: Berkala IImiah Bidang MIPA

(Science Periods EKSAKTA of MIPA) 


\begin{tabular}{ccc}
\hline 0 & 0,258 & 0 \\
20 & 0,081 & 68,6 \\
40 & 0,048 & 81,4 \\
60 & 0,049 & 81,0 \\
80 & 0,034 & 86,8 \\
\hline
\end{tabular}

From the table above shows that the effect of adding $\mathrm{TiO}_{2}$ to the increase in the percentage of degradation is also due to the formation of $\mathrm{OH}$ radicals on the surface of $\mathrm{TiO}_{2}$ particles, which causes an increase in the number of $\mathrm{OH}$ radicals that will degrade imidacloprid [5]. In addition, the surface of $\mathrm{TiO}_{2}$ has the ability to initiate chemical reactions, where in the water medium most organic compounds can be oxidized to $\mathrm{CO}_{2}$ and $\mathrm{H}_{2} \mathrm{O}$ [18].

\subsection{Fenthion compound degradation in sonozolysis}

Fenthion solution of $6 \mathrm{mg} / \mathrm{L}$ which was degraded by sonolysis and ozonolysis simultaneously for 80 minutes with a variation of $20,40,60$, and 80 minutes. The results of the degradation can be seen in Figure 3.

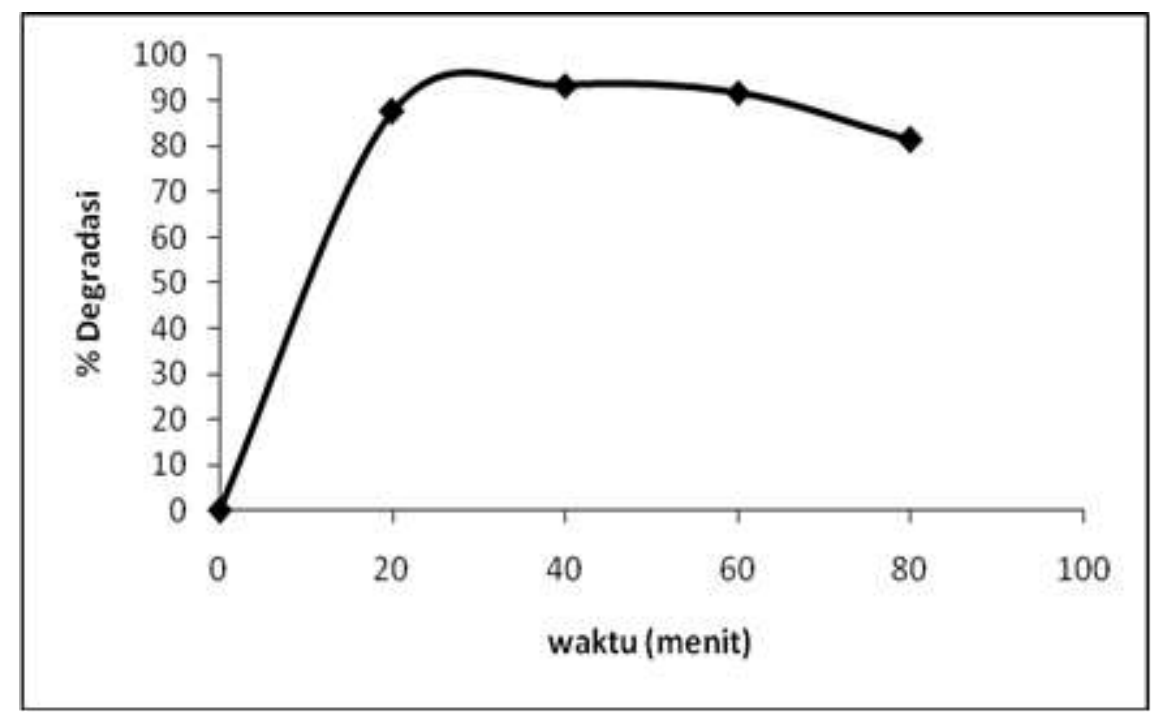

Figure 5. Fenthion degradation curve sonozolysis with $\mathrm{TiO}_{2}$-anatase addition

In Figure 3 shows that the percentage of degradation obtained by a combination of sonolysis and ozonolysis (sonozolysis) increased in the range of 20 to 40 minutes then decreased in the range of 60 to 80 minutes.

Sonolysis method and ozonolysis in the chemical process both produce $\mathrm{OH}$ radicals in aqueous solutions which will attack organic compounds to initiate the degradation process. Sonolysis with ultrasonic waves degrades fenthion compounds by producing $\mathrm{OH}$ radicals and other radical species on the inner surface of cavitation bubbles. Whereas with ozonolysis method, with

76 IEKSAKTA: Berkala IImiah Bidang MIPA

(Science Periods EKSAKTA of MIPA) 
the presence of ozone $\left(\mathrm{O}_{3}\right)$, resulting in the breaking of utusan bonds in the alkene, resulting in 2 new $\mathrm{C}=\mathrm{O}$ bonds. In the water phase, ozone can be broken down by hydroxide ions, $\mathrm{OH}-$, or conjugate bases from $\mathrm{H}_{2} \mathrm{O}_{2}\left(\mathrm{HO}_{2}^{-}\right)$to radicals $\mathrm{HO}_{2}{ }^{\bullet}$ and $\bullet \mathrm{OH}$.

\subsection{Effectiveness of Sonolysis, Ozonolysis and Sonozolysis Methods in degrading the compound fenthion}

The percentage degradation fenthion compounds obtained by the method sonolysis ozonolysis and sonozolysis for 80 minutes with the addition of anatase $\mathrm{TiO}_{2}$-listed in Table 5

Table 4. Comparison of percentage degradation of fenthion compounds by sonolysis, ozonolysis and sonozolysis at optimum time for 60 minutes

\begin{tabular}{cc}
\hline Method & \% degradation \\
\hline Sonolysis & 65,12 \\
Ozonolysis & 81,00 \\
Sonozolysis & 91,70 \\
\hline
\end{tabular}

From the table, it can be seen that the three methods above are the most effective method of sonozolysis with a percentage of degradation as much as $91.70 \%$. This comparison can be seen in Figure 4

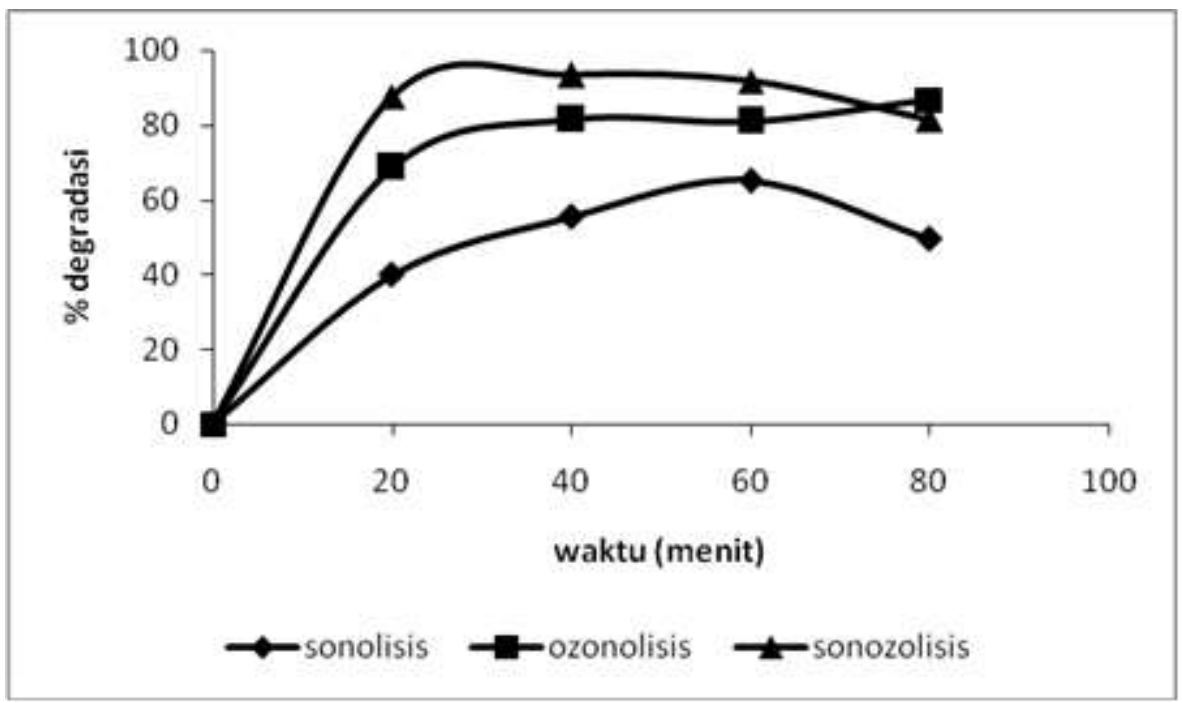

Figure 6. Comparison of percent degradation sonolysis, ozonolysis and sonozolysis against degradation percentage fenthion

77 IEKSAKTA: Berkala IImiah Bidang MIPA

(Science Periods EKSAKTA of MIPA) 
Figure 6 shows that the most percentage of fenthion degradation is the sonozolysis method. This is because during the ozonolysis process, ozone is broken down by hydroxy ( $\mathrm{OH}-$ ) ions into $\mathrm{OH}$ and $\mathrm{HO} 2$ radicals in the water phase, whereas with ultrasonic irradiation from the sonolysis process water will also be broken down into $\mathrm{OH}$ radicals in the presence of cavitation bubbles so that with the ozonation process accompanied by the sonolysis process, decomposition of ozone will occur in cavitation bubbles which will increase the amount of $\mathrm{OH}$ radicals formed.

\section{Conclusion}

From the research that has been done, it is found that the percentage of fenthion degradation is 6 $\mathrm{mg} / \mathrm{L}$ for 60 minutes using sonolysis method of $65.12 \%$, and ozonolysis of fenthion compounds is degraded by $81 \%$, whereas the sonozolysis method of fenthion compounds is audible at $91.7 \%$. Based on the data obtained it can be seen that the most effective method for degrading fenthion compounds is the sonozolysis method.

\section{Acknowledgement}

Thank you to the analyst of the Laboratory of the Physics and Pharmacology Pharmacy and the Faculty of Pharmacy, Andalas University who helped in the measurement using UV-Vis Spectrophotometer and HPLC, then thank you to Dr. Syukri Darajat, M.Si for the help of his substance, and thanks to the analysts at the Chemical Laboratory for his assistance in the smooth running of my research.

\section{References}

[1] Sudarmo, S. 1991. Pesticides. Kanisius. Yogyakarta. : 9-17.

[2] Cui C, Hu W J, Yan X, Addiego C, Gao W, Wang Y, Wang Z, Li L, Cheng Y, Li P, Zhang X, Alshareef H N, Wu T, Zhu W, Pan X, Li L J 2018 Intercorrelated In-Plane and Out-of-Plane Ferroelectricity in Ultrathin Two-Dimensional Layered Semiconductor In2Se3, Nano letters 18 1253-1258

[3] Lasut, M. T. P. Bobby and A. K. Veronoki, 2001, Comparison of Toxicity Levels of Several Pesticides (Endosulfan, Fentoat, BPMC, 2,4-D) By using milkfish (Chanos Chanos Forsk), the results of research by Sam Ratulangi University, Manado.

[4] Tietze, L. F., M. Bratz, 1998, Ozonolysis Mechanism on Organic Chemistry, Org. Syn. Coll, 9: 314

[5] Xu, Xian-wen, S. Hui-xiang, W. Da-hui, 2005, Ozonation with ultrasonic enhancement of p-nitrophenoI wastewater, J. Zhejiang Univ. Science B, 5 : 319-323.

[6] Wang, J, B. Guo, X. Zhang, Z. Zhang, J. Han, J. Wu, 2005, Sonocatalytic Degradation of Methyl Orange in the Present of TiO2 Catalysts and Catalytic Activity Comparison of Rutile and Anatase, J. Ultrasonics Sonochemistry, 12 : 331-337.

[7] Syukri, A., Safni, P.P. Roza, 2007, Degradation of Rhodamine B Compounds Sonolysis by Addition of TiO2 from Synthesis Through Sol-Gel Process, J. Ris. Kim., 1: (1), 64 69.

78 IEKSAKTA: Berkala IImiah Bidang MIPA (Science Periods EKSAKTA of MIPA) 
[8] Hakim, A., Safni, H. Suyani, T. Sakai, 2009, Degradation of 2,4 (Dichlorophenoxy) Acetic Acid in Pesticides Sidamin 865 AS Photolysis With Addition of TiO2-Anatase, J. Ris. Kim., 3: (1), 1-7.

[9] Yenni, N., Safni, H. suyani, 2010, Degradation of Paraquat Compounds in Gramoxone® Pesticides Sonozolysis With Addition of TiO2-Anatase, J. Ris. Kim., 3: (2), 145-150.

[10] Safni, Z. Zuki, C. Hayati, 2008a, Degradation of Alizarin Dyes in Sonolysis and Photolysis with Addition of TiO2-anatase, J. Pillar of Science, 17: (1), 31-36.

[11] Safni, Desmiati, H. Suyani, 2009a, Degradation of Dikofol Compounds in Pesticide Kelthane 200 EC by Photolysis With Addition of TiO2-Anatase, J. Ris. Kim., 2: (2), 140 - 148.

[12] Safni, Maizatisna, Zulfarman and T. Sakai, 2007, Naphtol blue Black Dyestuff Degradation by Sonolysis and Photolysis by Addition of TiO2-Anatase. J. Ris. Kim., 1: (1), 43 - 49.

[13] Safni, U. Loekman, and F. Febrianti, 2008b, Degradation of Sudan I Dyestuffs by Sonolysis and Photolysis by Addition of TiO2-Anatase. J. Ris. Kim., 1: (2), 164-170.

[14] Safni, Zulfarman, and F. sari, 2008c, Degradation of Methanil Yellow by Sonolysis and Photolysis with Addition of TiO2-Anatase, Indonesian J. of Materials Science, 11: (1), 47-51.

[15] Safni, Helma Nismar, H. Suyani, 2009b, Degradation of Triadimefone compounds in Bayleton $250 \mathrm{EC}$ pesticides by photolysis with the addition of TiO2-anatase, J. Impact, 5: (2), 6-10.

[16] Safni, S. R. Nofriani, H. Suyani, 2009c, Degradation of carbaryl compounds in pesticides Sevin $85 \mathrm{~S}$ photolysis by addition of TiO2-anatase, J. Impact, 6: (2), 19-23.

[17] Cabras, P., C. Tuberoso, M. Melis and G. M. Martini, 1992, Multiresidu Method for Pesticide Determination in Wine by High Performance Liquid Chromatography. J. Agric. Food Chem, 40: 817-819.

[18] Nurhamidah, 2005, Determination of HPLC Optimum Conditions for Separation of Imidacloprid, Prefenofos, and Deltamethrin Pesticide Residues in Chili (Capsicum annum), Journal of Indonesian Agricultural Sciences, 7: (2), 87 - 93.

[19] Gunlazuardi, J., F. H. Fajar and H. Suseno, 2002, Determination of Total Carbon Through Oxidation in Photocatalytic-Conductometry, Chemistry FMIPA UI, Depok. 